\title{
8
}

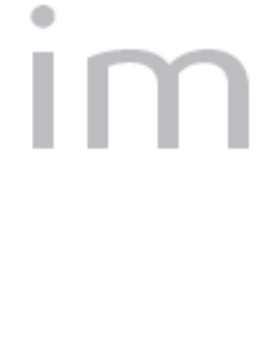

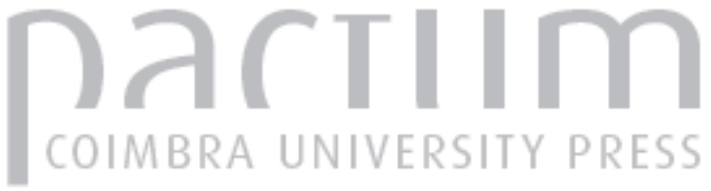

\section{Performance e Élenkhos no Íon de Platão}

Autor(es): Muniz, Fernando

Publicado por: Annablume Clássica; Imprensa da Universidade de Coimbra

URL persistente:

URI:http://hdl.handle.net/10316.2/24301

DOI:

DOI:http://dx.doi.org/10.14195/1984-249X_9_2

Accessed : $\quad$ 26-Apr-2023 15:29:33

A navegação consulta e descarregamento dos títulos inseridos nas Bibliotecas Digitais UC Digitalis, UC Pombalina e UC Impactum, pressupõem a aceitação plena e sem reservas dos Termos e Condições de Uso destas Bibliotecas Digitais, disponíveis em https://digitalis.uc.pt/pt-pt/termos.

Conforme exposto nos referidos Termos e Condições de Uso, o descarregamento de títulos de acesso restrito requer uma licença válida de autorização devendo o utilizador aceder ao(s) documento(s) a partir de um endereço de IP da instituição detentora da supramencionada licença.

Ao utilizador é apenas permitido o descarregamento para uso pessoal, pelo que o emprego do(s) título(s) descarregado(s) para outro fim, designadamente comercial, carece de autorização do respetivo autor ou editor da obra.

Na medida em que todas as obras da UC Digitalis se encontram protegidas pelo Código do Direito de Autor e Direitos Conexos e demais legislação aplicável, toda a cópia, parcial ou total, deste documento, nos casos em que é legalmente admitida, deverá conter ou fazer-se acompanhar por este aviso.

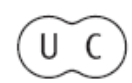




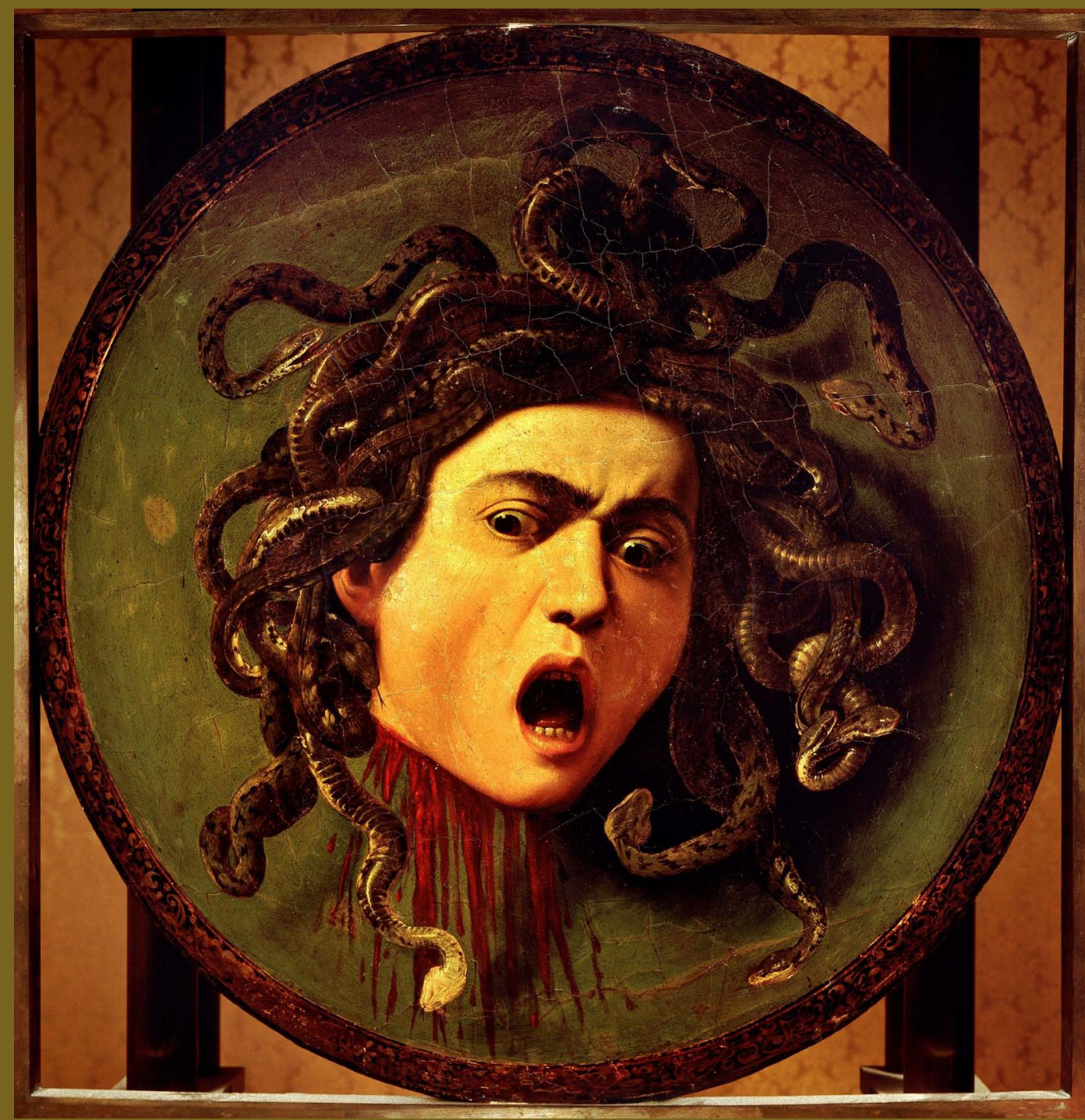

\section{R E V I S T A}
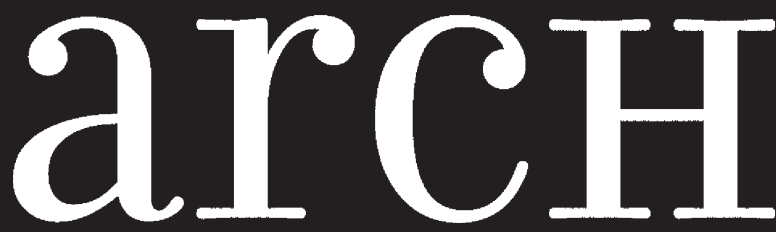
AS ORIGENS DO PENSAMENTO OCIDENTAL

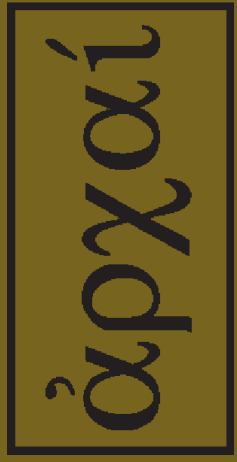

ARCHAI JOURNAL: ON THE ORIGINS OF WESTERN THOUGHT
arcHaI

arementam

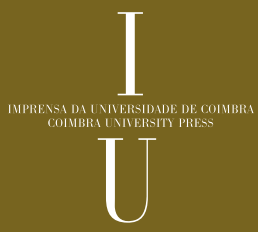

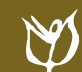

NNN 


\section{PERFORMANCE E ÉLENKHOS NO ÍON DE PLATÃO}

MUNIZ, F. (2012). "Performance e Élenkhos no Íon de Platão". Archai n. 9 , jul-dez 2012, pp. 17-26.

RESUMO: No Íon, a autoridade e a sabedoria de poetas e rapsodos são confrontadas por meios indiretos. 0 caráter oblíquo dessa estratégia impede o acesso direto ao conteúdo do diálogo e provoca inúmeros equívocos de leitura. Um fato contextual estimula mais ainda leituras equivocadas. A poesia tratada no Íon difere muito da forma como nós, modernos, a entendemos. Na Antiguidade grega, de base aural, a poesia era o modo privilegiado de conservação da tradição herdada, e permaneceu exercendo essa função capital até mesmo quando a escrita passou a desempenhar papel relevante na forma de composição e transmissão cultural. Neste contexto, o rapsodo representa uma autoridade que cobre praticamente todos os campos do saber. Autoridade enciclopédica, contra a qual Platão travou uma guerra não sem ambiguidades. 0 presente artigo busca revelar a motivação profunda que anima o Íon: a contraposição entre dois modos de comunicação, o da poesia e o da filosofia. Defende, ainda, que Platão, ao atacar a performance poética, busca, além de rejeitá-la, substituí-la pelo élenkhos socrático como modo de comunicação ideal para instrução e guia da vida humana.

PALAVRAS-CHAVE: Platão, Ion, hermenêutica, performance, élenkhos

Abstract: In Plato's Ion, the authority and wisdom of poets and rhapsodes are confronted by indirect means. The oblique character of this strategy prevents direct access to the content of the dialogue and causes misunderstanding. One contextual fact encourages further misreadings. The poetry treated in the Ion
* Universidade Federal Fluminense.

1. V. Goethe, "Platão como partícipe da revelação cristã" in Muniz (2011), p.108-112.

\section{Fernando Muniz*}

\section{Goethe e o Íon}

$\mathbf{G}_{\text {oethe leu no Íon um panfleto cheio }}$ de sarcasmo ${ }^{1}$. 0 prestígio de Goethe fez de sua reação indignada o paradigma para a recepção do Íon na Alemanha. A partir de Goethe, o Íon foi considerado ou apócrifo ou um equívoco indesculpável de Platão. Porém, Goethe identificou, com perspicácia, a presença do humor e da ironia no diálogo, o "fio polêmico", ainda que "dificilmente visível", que o atravessa. 0 reconhecimento de uma motivação implícita no diálogo é um dos marcos da leitura goethiana do Íon. Ele forneceu ainda indicações gerais para uma apresentação contextualizada do Íon. Uma delas seria entender não apenas contra o quê Platão estaria falando, mas também a favor do quê. 0 desenvolvimento desse duplo aspecto, segundo Goethe, seria o modo adequado de introduzir o diálogo. Supondo, ainda com Goethe, que é preciso distinguir o que Platão diz no Íon "com seriedade, brincadeira ou meia-brincadeira", proponho, neste artigo, seguir as indicações de Goethe - ainda que seja para rejeitar a sua visão de que Platão, no Íon, faz apenas um exercício de maldade aristofânica. 
is very different from how we, in modern times, understand it. In ancient Greece, where culture were aurally oriented, poetry was the main mode of conservation of the inherited tradition, and continued exercising this capital function even when writing began to play an important role in composition and cultural transmission. In this context, the rhapsode represents an authority that covers almost all fields of knowledge. An encyclopedic authority, against which Plato fought a war, not without ambiguities. This article seeks to reveal the profound motivation that animates the Ion: the opposition between two modes of communication: that of poetry and that of philosophy. It further claims that Plato, by attacking poetic performance in addition to rejecting it, tries to replace it with élenkhos as the ideal mode of communication for instruction and guidance of human life.

KEYWORDS: Plato, Ion, hermeneutics, performance, élenkhos

\section{As imagens da poesia e do rapsodo}

0 esclarecimento solicitado por Goethe não é tarefa simples de ser realizado. Separar o sério do irônico, a crítica da farsa é mais difícil do que pode ter parecido a Goethe e à tradição posterior a ele. Um intrincado subtexto e um complexo jogo discursivo fazem do Íon, como afirma Halliwell: “o inverso de um diálogo doutrinário" ${ }^{2}$ (HALLIWELL, 2002, p. 41). A motivação que o move ambiciona mais do que o diálogo estabelece, e seu subtexto é um ataque à autoridade e à pretensa sabedoria dos poetas, "culturalmente disseminadas, mas não examinadas, ou insuficientemente fundamentadas" (IDEM, p.41). Trata-se de autoridade e sabedoria tão enraizadas na tradição grega que talvez confrontá-las só fosse mesmo possível por meios indiretos. 0 caráter oblíquo dessa estratégia - empregada por Platão para tornar ilegítima a autoridade de rapsodos e poetas - impede o acesso direto ao conteúdo do diálogo e provoca os mencionados equívocos de leitura. 0 Íon, corretamente entendido, revela-se um marco na história da hermenêutica, sendo ele próprio, pela complexidade de seu jogo discursivo, uma provocação e um incitamento a sua interpretação.

Soma-se a isso, um fato contextual que contribui para os equívocos de leitura. A poesia tratada no Íon difere muito da forma como nós a entendemos, ou da forma como era entendida por Goethe e os Românticos ${ }^{3}$. Na Antiguidade Grega de base oral, a poesia era - ainda que não exclusivamente - o modo privilegiado de conservação da tradição herdada, e permaneceu exercendo essa função capital até mesmo quando a escrita, atrelada às novas formas emergentes de saber, passou a desempenhar papel relevante na forma de composição e transmissão cultural. 0 rapsodo, nesse contexto, exerce uma autoridade que cobre praticamente todos os campos do saber. Uma autoridade enciclopédica, contra a qual Platão travou uma guerra, não sem ambiguidades. Se levarmos em consideração esses aspectos, não podemos aceitar que o objetivo do Íon seja apenas - como supõem alguns comentadores - ridicularizar ou humilhar um rapsodo medíocre e simplório. 0 alvo do Íon deve ser buscado na contraposição estabelecida pelo diálogo entre dois modos de comunicação: o da poesia e o da filosofia. Defendo, portanto, que Platão, ao atacar o modo de comunicação da performance poética, tem como motivação profunda, além de rejeitá-lo, substituí-lo pelo élenkhos socrático como modo de comunicação ideal para instrução e guia da vida humana ${ }^{4}$.

Se identificamos corretamente os prós e os contras que operam na dinâmica invisível do diálogo, resta-nos ainda (i) saber como funciona a crítica à performance poética, (ii) identificar quais são os meios argumentativos e dramáticos orquestrados por Platão para atingir esse objetivo, e (iii) mostrar como tais meios solidários estão integrados na estratégia geral do diálogo. Julgo que o reconhecimento dessa estratégia elimina a sensação de farsa e falácia que costuma acompanhar as leituras superficiais do Íon. A referida sensação seria apenas o efeito negativo da elaborada tessitura do diálogo. ${ }^{5}$ A leitura positiva que desatam certos nós dessa trama revela seu alvo mais distante. Uma das distinções necessárias a fazer, em primeiro lugar, é a das três imagens da poesia e da performance poética oral que aparecem sobrepostas no diálogo. A primeira imagem, a mais verossímil (se levamos em consideração os testemunhos que temos sobre o comportamento dos rapsodos na Grécia clássica) é construída pelo próprio rapsodo. Nesta, são enfatizados o caráter empático da performance, a reação emocional da
3. Halliwell (2002), p. 41: "In my view, briefly stated, is that Ion is the very reverse of a doctrinaire dialogue. It is a subtle Platonic exercise in the use of schematic dialectic to hint at much more that it ever states." [...] "[I]ts subtext is an attack on culturally widespread but unexamined, or insufficient substantiated, claims for the authority and wisdom of poets."

4. Sobre o fato dos românticos terem reconhecido - por uma leitura equivocada - no Íon o precursor das teses românticas, v. Stern-Gillet (2004), p. 169: “Some historians of aesthetics [...] have sought to identify in it [Íon] the seeds of the post-Kantian notion of 'art' as non-technical making, and to trace to it the Romantic conception of the poet as a creative genius. Others have argued that, in the Ion, Plato has Socrates assume the existence of a techne of poetry. In this article, these claims are challenged on exegetical and philosophical grounds."

5. Minha posição aproxima-se da de Yunis (2003): "Plato's dialogue Ion, which depicts a Homeric rhapsode in de middle to late fifth century, considers the manner in which poetic texts are received. Plato's irony is conspicuous; his purpose is clearly not historical. Rather he puts two modes of poetic reception in sharp contrast in order to illustrate their essential characteristics." (pp. 190-1). Há aproximação, mas não identificação. 
plateia e a participação ativa do rapsodo/poeta no processo performático. Em 535b, por exemplo, Íon reconhece que, quando canta algumas passagens especialmente impactantes da Ilíada ou da Odisseia, é transportado para os cenários narrados, fica transtornado, com olhos cheios de lágrimas, de pelos eriçados, coração disparado etc. Sócrates pergunta então se Íon percebe que a mesma coisa se passa com a plateia. Íon afirma que não apenas percebe, mas que precisa prestar muita atenção nos espectadores, e brinca: "se eu não os fizer chorar, quem chorará serei eu depois pelo dinheiro que perderei". Essa imagem do rapsodo que controla o processo performático será insistentemente ignorada por Sócrates durante todo o diálogo. Íon é coagido a se identificar com imagens inteiramente diferentes de seu ofício, imagens que Platão elabora a partir de elementos retirados da tradição e do contexto hermenêutico do seu tempo - ainda que ressaltando nelas os traços necessários para que a desqualificação da autoridade dos rapsodos e poetas venha a se realizar.

\section{0 Rapsodo como Hermeneuta do Sentido Oculto}

No início do diálogo, vemos Íon chegar vitorioso de Epidauro a encontrar, por acaso, Sócrates. De imediato, o filósofo confessa ter inveja dos rapsodos. Eles seriam dignos de inveja por estarem sempre muito belamente vestidos e em convivência com os poetas, especialmente, Homero. A evidente ironia na inveja assumida por Sócrates estimula o leitor a pisar no terreno movediço sobre a qual a trama do Íon é construída.

Fisgado pela "confissão" de Sócrates, Íon presta atenção agora nas razões da inveja de Sócrates: os rapsodos "sabem de cor" (ekmanthánein) não apenas os versos (tà épe), mas também “o pensamento" (diánoian) do poeta. Tal seria, segundo ele, a condição fundamental para o bom desempenho dos rapsodos: "É impossivel que ele possa desempenhar belamente seu ofício se não 'entender' (suníemi) o sentido dos 'versos' do poeta" (tá legómena) (430c). Com terminologia calcada em verbos de cognição (ekmanthánein, suníemi), Sócrates apresenta uma imagem bem diferente daquela, historicamente mais plausível e na qual Íon espontaneamente se reconhece. Nesta outra, ele é chamado de hermeneús, um tradutor do sentido dos versos do poeta para a audiência. A ambiguidade do termo hermeneús é a chave do diálogo. Designa, neste contexto, o detentor de um conhecimento semântico que o habilita a traduzir de uma língua a outra. A língua é, portanto, o paradigma hermenêutico que, por analogia, esclarece a natureza da habilidade do rapsodo; o objeto dessa técnica é o sentido das palavras ou a intenção (diánoia) do poeta; a tradução, o resultado prático da atividade do rapsodo.

Surpreendentemente, Íon aceita essa descrição do seu ofício. Afirma depender desse tipo de conhecimento, e acrescenta, em 530c, que isso foi o que deu "mais trabalho (érgon) na minha técnica", mas, por que o rapsodo aceitaria o papel de comentarista de Homero? Não fosse pela vaidade do rapsodo e pela ironia platônica, seria difícil compreender essa identificação (na verdade, como veremos, uma das artimanhas do diálogo é fazer variar a imagem do rapsodo com seu próprio consentimento). Na Grécia clássica, pelo que sabemos, a atividade do rapsodo se reduz à recitação performática, sem espaço para o comentário ou para a explicação interpretativa. Essa identificação de Íon soa, portanto, estranha. Como a tradição oral que sustenta a prática do rapsodo não estabelece distinção clara entre composição e exibição, - cada exibição é uma composição - não teria sentido tratar a performance poética oral como uma atividade de crítica interpretativa. Na sequência de sua fala, Íon - deslumbrado talvez por se enxergar caracterizado como conhecedor dos pensamentos do poeta - afirma dizer coisas mais belas sobre Homero que Metrodoro de Lâmpsaco, Estesímbrotos de Taso, entre outros. Com essa referência a técnicas de interpretação de Homero, - especialmente, a alegórica - Platão nos dá uma indicação clara do tipo de coisa que põe em jogo.

A palavra "alegoria" - que significa, literalmente, "dizer outra coisa" — surge bem depois do período clássico e tem uma interessante pré-história. No final do séc. VI, alguns admiradores de Homero, movidos pelo desejo de defendê-lo das acusações de impiedade, inventaram esse procedimento de lei- 
tura chamado posteriormente de "alegoria". Porfírio menciona essa técnica quando diz que as "histórias descabidas que Homero conta sobre os deuses podem ser defendidas apelando para seu modo de expressão, sua léxis, assegurando assim que tudo foi dito de forma alegórica" ${ }^{6}$. Ainda segundo Porfírio, esse tipo de defesa de Homero seria muito antiga e remontaria a Theagenes de Regium ${ }^{7}$. Theagenes e outros ferrenhos partidários de Homero estariam entre os que tentaram defender o autor da Odisséia dos ataques racionalistas de detratores como Xenófanes. Como se vê, a famosa disputa entre a filosofia e a poesia tem raízes profundas.

Usando muitas vezes etimologias fantásticas, a engenhosa leitura alegórica buscava encontrar por trás das divindades homéricas os conceitos abstratos da cosmologia nascente. Tinha a vantagem de, além de corrigir o comportamento das divindades tradicionais, tornar a épica homérica mais palatável ao gosto "científico" da época. Plutarco, no início da nossa era, instrui-nos mais precisamente sobre a tática hermenêutica desses defensores da poesia. Segundo ele, a alegoria tinha outro nome na origem; chamava-se hypónoia (sentido escondido ou sentido oculto), termo que encontramos no séc. V, em Tucídides, em Xenofonte e, para o que nos interessa, em Platão ${ }^{8}$.

Com essa menção à alegoria, Íon se insere voluntariamente no grupo dos hermeneutas da hypónoia. Incitado por Sócrates a identificar sua prática com a de um hermeneús, - tradutor da diánoia do poeta - o rapsodo aceita ser o mediador de um modo de comunicação triádico (poeta-rapsodo-auditório), assumindo possuir um tipo de conhecimento segundo o paradigma da decifração do sentido. Para que isso seja mostrado de modo claro, Sócrates pede, então, uma epídeixis - uma exibição. Quando Íon se diz disposto a fazê-la, Sócrates alega então não ter tempo para assisti-la. A recusa da epídeixis por Sócrates, reiterada durante todo o diálogo, deve receber de nós leitores a mesma ênfase que Platão the dá. A performance poética é excluída, no início, pela mera recusa de sua apresentação, mas, no fim, por uma redefinição do seu sentido que terá como consequência a desqualificação de sua forma (performática) e neutralização de seu conteúdo (poético) pretensamente cognitivo.

\section{Performance e Élenkhos}

0 termo epídeixis, traduzido por performance, reforça o jogo ambíguo do diálogo. Uma deîxis é uma forma de mostrar, de fazer ver; com a preposição epi-, a ênfase deste mostrar recai na relação com uma audiência - é um mostrar algo diante de um público. Uma epídeixis é, portanto, uma exibição pública, uma performance. Nesse sentido básico, epídeixis tinha ainda, na sua origem, uma variedade de formas. Todas apresentando a mesma função elementar de fazer uma "exibição ou prova de uma excelência ou habilidade". Segundo Yunis, a demonstração pública de conhecimento ou tékhne:

was a specific form of epideixis. The early evidence (given later) implies that epideictic activity covers a wide range of methods and types of oral discussions, presentations, and speeches, as well as subjects, for in the late fifth century it is virtually impossible to separate the epideictic from the agonistic, or the epideixis from oral performance. (THOMAS, R. in YUNIS, 2003, p. 174).

No final do V e começo do IV séc., a epideixis ainda estava distante do gênero de discurso consagrado por Aristóteles como epidêutico. ${ }^{9}$

Sócrates recusa a performance de Íon por mais duas vezes, em 530d e em 536d. Além disso, quando pede ao rapsodo que lembre uma passagem de Homero, corta a fala de Íon no meio, com um ríspido "basta!" (askei), e dali em diante, ele mesmo faz a citação das passagens de Homero, destituindo o rapsodo de sua própria função. No final do diálogo, em 541a, esta tática torna-se ainda mais evidente, quando - não sem crueldade - Sócrates acusa o rapsodo de não ter feito a performance que ele pediu: "tu foste injusto comigo, Íon, prometeste a performance, mas não a fez". 0 jogo ambíguo da deîxis permite que Sócrates diga que Íon não "mostrou" o que prometera. Na verdade, Íon falhou ao tentar fazer a "demonstração" discursiva de sua habilidade no modo de apresentação do élenkhos; no modo performático, ele nem chegou a tentar: foi impedido por Sócrates.

A contraposição entre epídeixis e élenkhos é uma constante estrutural do diálogo. A recusa da
6. V. também Kahn (1993), p. 378. Bloom (1987), p. 393 : "Íon was caught in a sophistic argument".

7. Citado por Ford, A. (2002), p.70. Ford, no entanto, associa Theagenes aos rapsodos, que, segundo ele, "also commented on the songs they performed" (p. 70) Ford usa o Ion como elemento de prova: "The rhapsodo portrayed in Plato's Ion can recite passages from Homer on cue, but also can 'embellish' (kosmein) the poet by discoursing on his 'many fine thoughts' (polla kai kalla dianoiai, Ion 530d)". Curiosamente, Ford toma o texto platônico como um documento histórico que retrata fielmente a prática dos rapsodos. Mas como bem observa Guthrie, o Ion é a única fonte para esse conjectura. V. nota 7 .

8. Guthrie (1975), p. 201:

"Outside the Ion there is no evidence that these commentators were ever called rhapsodes, and the most reasonable conclusion is that Ion (who is otherwise unknown, and for all we know invented by Plato for his own purposes) is exceptional among rhapsodes in combining recitation with exposition." Essa exceção precisa ser explicada. Julgo que apenas na estratégia geral do Íon podemos encontrar uma resposta plausível.

9. Tucídides (II.41.4), Xenofonte, (Banquete III, 6), Platão (República II, 378d). 
10. Thomas, R. in Yunis (2003),

pp. 173-4: "What form, or forms, does the display performance actually take? And what is the relation of oral performance to written text? We should not assume that the epideixis of the late fifth and early fourth centuries corresponded simply to Aristotle's epideictic genre of speeches (genos epideiktikon). Aristotle's definition belonged to a later, more text oriented period, when genres had crystallized and oral delivery had slightly different connotations. In the Rhetoric (3.12), he distinguished the 'agonistic style', which is for oral delivery, from the 'written style'; the agonistic style encompassed speeches fo the assembly and for the courts, whereas the written style was epideictic: 'The epideictic style is most like writing for its objective is to be read" (Rhetoric 3.12.5)."

11. Stern-Gillet (2004) p.177. “[...] unlike most of the early dialogues, the Ion is not fully aporetic. Socrates is portrayed as being in a unusually loquacious mood, besides cross-examining his interlocutor and exposing his slow wit, he offers an alternative account of the genesis of poetry. This account, which is sandwiched between the two parts of the elenchus, is the pivot of the dialogue."

12. Platão inventa essa visão do entusiasmo. Não há na tradição anterior nada semelhante ao que ele propõe no Íon. Ver para isso Tigestedt, Jacyntho Brandão in Muniz (2011).

13. Yunis (2003), p. 191. “[...] he puts two modes of poetic reception in sharp contrast in order to illustrate their essential characteristics. When Ion performs Homer, he functions as the poet's surrogate, and his recitation of the text moves the audience to tears, terror, and amazement (Ion 535e). The

audience's emotional reaction, which is pleasurable for them and wins the rhapsode admiration, enables them to experience vicariously the travails of Achilles, Odysseus, and the other characters. As if to signal the uncanny power of this performance, Plato ascribes it to divine inspiration (Ion 536b). This reaction to performed poetry was also described by the sophist Gorgias (Helen 9): Those who hear it [poetry, poiesis] are overcome with fearful shuddering, tearful pity, and mournful yearming, and through the words [of the epídeixis vem sempre acompanhada de uma pergunta que permite a passagem da performance ao élenkhos. 0 élenkhos distingue-se da epídeixis como um outro modo público de mostrar alguma coisa. Ainda que a dialética seja sempre restrita a dois interlocutores, sua dimensão pública é indispensável. E como o exame dialético se dá sempre a partir do que foi dito e das consequências necessárias do que já foi afirmado, o termo grego mais apropriado para designá-lo é apódeixis, a demonstração.

A recusa de epídeixis e a exigência de apódeixis são, pois, complementares. É esse tipo de demonstração que Sócrates cobra incessantemente de Íon em substituição à performance. Vejamos uma situação típica: Íon aceita ser tradutor da diánoia de Homero - isso implica que deve responder sobre a questão da natureza desse conhecimento. 0 tipo de questão que permite a passagem da epídeixis ao processo dialético de refutação é, nesse caso, a seguinte: "você é hábil apenas em Homero, ou é também em Hesíodo ou Arquíloco?" A resposta de Íon é imediata: "só falo bem sobre Homero". É a deixa para a primeira refutação de Íon (531a-532c). “Homero não fala sobre as mesmas coisas que os outros poetas?" Íon defende-se: "realmente Homero faz isso, mas de um modo muito melhor". Sócrates retoma: “aquele que sabe reconhecer o que está bem feito, não deve reconhecer também o que está mal feito?" Conclusão inevitável: se Íon é hábil em Homero, deve ser também hábil nos outros poetas. Diante disso, Íon não sabe o que dizer, só sabe que "fala belamente e com fluência sobre Homero, em relação aos outros fica em aporia, sem ter o que dizer, sem interesse". Sócrates é então instado por Íon a explicar esse fenômeno. Como é possivel a existência desse conhecimento irredutível em sua especialidade? A pergunta aponta para uma resposta mais adequada ao tipo de experiência que a performance poética fornece.

\section{0 Rapsodo como hermeneuta da transmissão}

Neste momento, o diálogo transforma-se sintomaticamente em um solene monólogo (533d$-534 \mathrm{e})^{10}$. Após afirmar que não era sábio (532d: “sábios são vocês, os rapsodos, os atores, e todos os que cantam poemas"), Sócrates expõe a sábia doutrina do entusiasmo de um modo quase entusiasmado. De acordo com a doutrina, Íon não canta Homero por tékhne, mas por theía dýnamis (potência divina). Essa potência divina é comparada a uma pedra, um ímã que atrai um anel de ferro e transmite (entithesi) a ele seu próprio poder de atração, fazendo com que o anel atraia outros anéis e, por sua vez, transfira a eles sua força, formando assim um circuito integrado de transmissão.

Vemos surgir assim uma nova imagem do rapsodo e do poeta. Agora, eles são éntheoi, ou seja, "têm um deus dentro", são elos da cadeia transmissora emanada pela potência divina; e consequentemente, não podem estar de posse de sua razão, não podem ter diánoia. A intervenção divina aqui é entendida de um modo completo: o deus expulsa da mente quem a habitava para possuí-la inteiramente ${ }^{11}$. Essa nova visão do entusiasmo exige um novo sentido para a comunicação poética e um novo sentido para hermeneús - não mais "tradutor", mas, agora, "transmissor". Assim, Platão inventa a hermenêutica da transmissão magnética do sentido. Íon aceita — de bom-grado - essa nova imagem. Chamado de hermeneús, transmissor das mensagens divinas, ele se diz tocado pelas palavras de Sócrates e concede, envaidecido, que é por privilégio divino que os bons poetas são os transmissores das mensagens dos deuses para os mortais. Isso permite que Sócrates conclua que "os rapsodos transformaram-se agora em transmissores dos transmissores". Tais transformações sucessivas da identidade do rapsodo o associam, como veremos adiante, ao caráter proteico da poesia: mutabilidade e diferenciação incessantes. Eis então as três imagens distinguidas:

1. 0 rapsodo performático ciente de seus recursos e atento aos efeitos que produz;

2. 0 rapsodo hermeneús- tradutor, comentarista da diánoia ou da hypónoia de Homero;

3. 0 rapsodo-entusiasmado, possuído pela divindade, portanto, hermeneús -transmissor, boneco de ventríloquo da divindade.

A sobreposição dessas imagens gera vários problemas de interpretação do diálogo. Alguns comentadores $^{12}$ percebem essa dificuldade. Platão teria construído dois Ions, um cantor, outro, comentador 
de Homero; um, entusiasmado, outro, não. Pede epídeixis, mas cobra apódeixis. 0 fato é que o rapsodo só se identifica espontaneamente com a figura do hábil performer, - imagem que ele mesmo ajudou a construir — mas não aceita facilmente nem a imagem do tradutor-comentarista de Homero, nem a do transmissor em transe que é movido pelo entusiasmo na forma da possessão completa. Quando oferece, pela segunda vez, a sua performance a Sócrates, Íon parece enfim dizer o que realmente pensa: “se me ouvisses falar sobre Homero, não acreditarias que estou possuído" (536d). Mas Sócrates insiste na sua recusa da performance: "é claro que quero ouvi-lo", diz ele, "mas não antes de me responder a uma questão." (536e). Mais uma vez, é uma pequena questão que faz a passagem da epídeixis ao élenkhos.

\section{Performance e Hypónoia}

Sabemos hoje sobre a efervescente cena de interpretação da poesia do séc. V - a menção de Íon a Metrodoro e Estesímbrotos refere-se a esse contexto $^{13}$. Recentes descobertas (Papiro Derveni, 7.3-7) atestam o uso de variadas técnicas de interpretação, como a analogia, a etimologia e a mencionada alegoria $^{14}$. Tais tendências hermenêuticas tinham como pressuposto a crença de que é impossível entender o sentido do poema no ato de sua audição. Isso é dito de modo explícito no fragmento do Derveni ${ }^{15}$. Técnicas de interpretação da poesia, como a da hypónoia, entre outras, são, de modo geral, reações críticas à recepção pública da poesia na forma da epídeixis, da performance oral: o modo de apresentação original da poesia ${ }^{16}$. A fluidez e a transparência que são condições para a performance poética implicam a inseparabilidade entre a palavra e seu sentido. Essas técnicas tentavam bloquear exatamente a experiência emocional de fluidez e da transparência por meio de uma operação mínima: distinguir a palavra do seu sentido. Colocado em funcionamento esse princípio, uma profundidade semântica é aberta, várias camadas da diánoia do poeta são liberadas, e o que o poeta "realmente" queria dizer passa a ser objeto de litígio. A autoridade da intenção do poeta passa tanto a legitimar certas interpretações quanto a recusar outras tantas.
As performances poéticas não permitiam distância entre a palavra e o sentido. Quando a distância entre a palavra e o sentido foi, hermeneuticamente, aberta, não houve mais como fechá-la. Platão herda e adota esse princípio geral, mas o adapta a seus interesses. ${ }^{17}$ Logo no início do Íon, vemos Sócrates introduzir a distinção entre palavra e sentido. Seu primeiro movimento tático é fazer Íon aceitar que uma coisa são os versos que ele pode saber de cor e que outra coisa é a diánoia do poeta. Na epídeixis, não há como os espectadores distinguirem o que é dito do significado do que é dito. É nesse sentido que a retórica ${ }^{18}$, para Platão, produz o mesmo efeito negativo: o retórico modela suas composições de tal modo que a audiência fica incapacitada de considerar o que ele diz de uma forma diferente daquela que ele diz. Envolvidos emocionalmente, os espectadores não precisam "compreender" o sentido da palavra poética. Ainda que nem tudo seja transparência em um poema, quando ocorrem situações ou expressões opacas, elas são ignoradas para que a experiência poética possa manter seu ritmo e fluência. 0 sentido da performance é, portanto, construído em um fluxo da transparência; qualquer distanciamento ou obstáculo bloqueia e anula o efeito de sentido. Toda opacidade que não pode ser ignorada interrompe 0 fluxo da intensidade emocional - e é, neste sentido aporética e dialética. A recepção da performance poética é, necessariamente, acrítica e passiva. Nos termos da doutrina do entusiasmo, a transmissão do sentido deve se efetivar por meio magnético ou viral, sem que nenhuma operação intelectual, nenhuma inferência, nenhuma dedução, interrompa seu fluxo.

Epídeixis, como vimos, opõe-se frontalmente a apódeixis. Como forma de demonstração pública, a apódeixis tornou-se mais tarde modelo de prova filosófica. No contexto de que estamos tratando, ela tinha outros aspectos distintivos. Usado de preferência a epídeixis, o termo apódeixis designa um modo de exibição pela prova, operando assim por meio de inferências e deduções. É com apódeixis que Heródoto introduz sua obra, como uma demonstração pública. Nos tratados hipocráticos sobre a natureza do homem (ch 2.5.j) lemos "irei demonstrar [apodeixo]... fornecer provas... revelar poetry] the soul experiences a feeling of its own over the good fortunes and ill-farings of other people and their affairs' (trans. McKirahan, adapted)".

14. "The evidence for these figures [Metrodoro e Estesimbrotos] and their work is meager, but it is clear that in the late fifth century they were prominent among those who began to interpret poetry in a way that had no regard for the experience of performed poetry. Metrodorus equated the Homeric gods and heroes with heavenly bodies and substances in an allegorical manner (DK 61.3-4). Stesimbrotus, a writer on contemporary fifth-century historical figures, also wrote about problems raised by the wording of Homer's text (FGrH 107 F 21-5)". Yunis (2003), p. $193-4$.

15. Yunis (2003), pp. 195-6: “The best surviving extended example of poetic interpretation before Plato is the text preserved, imperfectly, on the Derveni papyrus. [...] The author interprets not Homer but a cosmogonic poem ascribed to Orpheus, distinguishes between the poem's words and its meaning, as in this passage, which precedes his interpretations of particular verses and forms a general statement of his method (Derveni papyrus 7.3-7): 'And the true [nature] of the words cannot be said even though they are spoken. The poem is a [strange] one and riddling for human beings. But [Orpheus] intended [by means of it] to say not [contentious] riddles, but rather great things in

riddles.' 23 (trans. Laks and Most, adapted). [...] The word-meaning distinction is deployed, for instance, when the interpreter considers the poet's use of riddling language (9.10, $13.6,17.13)$, synonyms (10.2-10, $11.5,12.3-7)$, allegory (16.1), and etymology (22.7-13, 26.1-2)."

16. Yunis (2003), pp. 196: “At one point, the Derveni author parenthetically explains the fact that the poem's true meaning has not been grasped by people who have heard the poem (20.2-3): 'It is not possible to hear and at the same time to learn the meaning of the words' ('para ou gar oion te akousai homou kai mathein ta legomena', trans. Laks and Most)."

17. Esta posição se matém, mesmo se aceitarmos a hipótese de que a hermenêutica dos Homeridas tenha surgido para defender Homero dos Filósofos. Ver pág. 5-6. 
18. Yunis (2003), p. 190. “Historically, Thucydides and Plato reflect most clearly the explicit concern with hermeneutics - the systematic pursuit of understanding discourse - that arose around 400 b.c.e. in reaction to the changes then occurring in the way discourse was being composed and reachin its audience. The increased use of written texts, in addition to and alongside traditional modes of poetic and rhetorical performance, caused writers to consider how texts were and could be interpreted. 4 Thucydides and Plato recognized that interpreting a written tex was, in certain respects, different from interpreting orally delivered discourse. For written texts that have subtle didactic aims and require the reader to exercis critical thinking, as is the case with the texts of Thucydides and

Plato, the reader's interpretive problem becomes acute. Insofar as such texts were new, so too were the corresponding problems of interpretation." Yunis 190

19. Ver Muniz (2011), Cap. 3:2: A Retórica e a Potência da Aparência.

20. Platão é um crítico da técnica da hypónoia em Rep, II, 378d5 8, Sócrates afirma: “0s jovens não podem distinguir o que é uma hypónoia do que não é uma hypónoia [ho gar neos ouch hoios te krinein hoti te hyponoia kai ho me] e as opiniões que formam nessa idade não podem ser erradicadas ou alteradas. É importante observer, como o faz Lear (2006), que "hyponoia [...] is quite literally the under-thought. Indeed, it is an 'under-thought' in another sense: it enters de psyche beneath radar of critical thought", p.27.

21. Górgias, 489d; Rep., 331e Apologia, 21b; Banquete, 200d; Laques, $195 \mathrm{~d}$

22. Yunis (2003), p. 209-210. "When the poetic interpreters seek the meaning of a poem, they consider what the author of the poem intends, this is necessarily the absent author whom Plato finds so troublesome. In Thucydides' case, the author conspicuously calls attention to himself as author and to the 'clear view' of events that he promises the reader and makes available through critical reading. Plato, on the othe hand, hides himself as author; he refrains from overtly signaling his presence or didactic purpose to the reader. He does not identify himself or his meaning with Socrates or as causas necessárias". A tradução aqui de apodeixo deve ser entendida como "vou mostrar de modo decisivo", significando apresentar evidências, provas e indicações inequívocas.

0 élenkhos, como uma forma de apódeixis, cava, à sua maneira, uma distância entre a palavra e o sentido ${ }^{19}$. Seu traço típico é a questão: o que significa essa palavra? 0 que essa pessoa quer dizer com isso? Ti légei; ${ }^{20}$ transparência e opacidade são aspectos complementares da dialética e motores do élenkhos. Como há sempre sentido implicado em tudo que pode ser dito e não há discurso que ofereça evidência absoluta, há sempre opacidade, obstáculo, aporia. Em Apologia 21b, diante do oráculo enviado pelo deus de Delfos, Sócrates se pergunta “o que o deus quis dizer com isso?". Derivado de uma hermenêutica oracular, o élenkhos é um modelo de leitura crítica: busca analisar meticulosamente o sentido das palavras, as suas implicações, e o que podemos inferir a partir dele. Por essa razão, é oferecido como alternativa racional para a epídeixis como a forma ideal da instrução ética. ${ }^{21}$

Dito isso, podemos ver que no modelo hermenêutico triádico - poeta/tradutor/audiência - o peso recai na função cognitiva e mediadora do tradutor. Uma diferença qualitativa articula esses três elementos de modo que as operações de passagem de um a outro não se efetuam sem resistências, obstáculos, opacidades. Tais limites aporéticos precisam ser ultrapassados, seja pela tarefa de decifração do pensamento do poeta, seja na forma de comunicação do sentido à audiência. Segundo o modelo apodêitico, o poeta concebe, o rapsodo traduz, a audiência recebe.

No modelo quaternário - Musa/poeta/rapsodo/audiência - a diferença entre os elos da cadeia não é mais qualitativa. A diferença que percorre a cadeia é, sim, quantitativa ou de grau. Da Musa - a fonte - à audiência, é o mesmo fluxo de transparência de sentido que as percorre. $E$ mesmo que se suponha a possibilidade de haver um decréscimo de intensidade na passagem de um elo a outro, essa redução será ainda de ordem quantitativa. Não há operação intelectual de compreensão do sentido que possa qualificar a recepção como melhor ou pior; 0 sentido simplesmente passa - segundo o modo da afetividade e do contágio - de um elo a outro da cadeia em uma fluência absoluta ${ }^{22}$.

\section{Conclusão: Élenkhos e Paradoxo}

Podemos extrair da conversa socrática, portanto, duas formas de comunicação entre deuses e homens: a comunicação intensiva, eletromagnética, da qual poetas e rapsodos são os transmissores; e outra, dialética, mais afinada com a prática filosófica, construída a partir de operações intelectuais. Por meio da comunicação intensiva ${ }^{23}$, os deuses transmitem "muitas coisas belas", no mesmo ato em que impedem que haja um acesso discursivo às suas significações primeiras; através da segunda, a demonstrativa, eles fazem com que os homens saibam que, eles, os deuses, são os verdadeiros autores da poesia $^{24}$. Neste sentido, são processos opostos, mas completares: a demonstração prova que o intensivo não pode ser demonstrado. A maior evidência disso, segundo Sócrates, é o caso de Tínico de Cálcis que nunca fez um poema digno de ser recordado, mas compôs o mais belo poema em honra de Apolo. Os mais belos poemas são tomados assim como provas de sua origem divina. É o que diz Sócrates:

"Pois um deus, como me parece, nos demonstra (endeíxesthai), sem deixar dúvidas, que esses belos poemas não são humanos, nem são obras de homens, são divinos e obras de deuses" [PATÃO, ION 534e]

Os poetas não passariam de transmissores dos deuses, já que são inteiramente possuídos por eles. Paradoxalmente, o mais belo poema, produzido pelo entusiasmo, é, na realidade, uma demonstração que o neutraliza: "É para oferecer uma demonstração (endeiknýmenos) disso [de que os poetas não são os autores dos poemas] que o deus coloca, de propósito, na boca do mais medíocre poeta, o mais belo poema." (534d)

A resposta à questão posta por Sócrates ("por que o deus tira a razão desses homens e os usa como seus funcionários como o faz com os profetas e adivinhos?") é decisiva porque faz convergir e sobrepor os dois modos de comunicação: a poesia transmitida magneticamente é uma éndeixis da di- 
vindade que dá, assim, uma indicação inequívoca de que não são os poetas que dizem coisas valorosas, mas, sim, a própria divindade que se dirige a nós através deles. Desse ponto de vista, o poema de Tínico de Calcis tem dupla face. Por um lado, é uma intervenção da Musa, capaz de mobilizar o circuito de comunicação intensiva; mas, por outro, é outro tipo de signo - que não revela seu sentido oculto sem que operações intelectuais sejam realizadas. Em outros termos, a demonstração fornecida pelo poema de Tínico produz, na superfície, o efeito magnético, mas, na profundidade, revela a intenção dos deuses. Assim, o paradoxo exposto pelo poema de Tínico de Calcis - como o melhor poema pode ser produzido pelo pior poeta? - revela ser o motor da investigação sobre a poesia. Sócrates equipara o paradoxo de Tínico ao oráculo fornecido por Apolo. 0 que os deuses querem dizer quando fazem Tínico cantar o melhor poema? 0 melhor poema esconde uma endeixis na sua epídeixis: demonstra que os poetas não são os autores e não sabem do que falam. Isso explica, enfim, a origem do monólogo de Sócrates: a doutrina do entusiasmo seria o resultado de um élenkhos, de uma investigação sobre o enigma que o poema de Tínico representa.

No Eutífron, 11b-c, Socrates diz ter em Dédalo, o artífice do labirinto, seu antepassado e inscreve-se numa linhagem que remonta a Hefesto, a dos fabricantes de estátuas móveis. Isso explica tanto o fato de 'as estatuas de palavras' construídas por ele escaparem quanto as construídas pelos seus interlocutores. No final do diálogo (15b-d), Sócrates retoma o tema. Afirma que Eutífron, por estar sempre retornando à posição anterior, prova ter uma habilidade técnica superior ao próprio Dédalo e a ele mesmo, Sócrates, já que faz as 'estátuas' andarem em círculos, mas que a verdade que há dentro dele deve ser agarrada, como o foi Proteus e só liberada quando ela se pronunciar. Como se vê, a verdade, no contexto do Eutífron, pode ser tão multiforme e dissimuladora quanto à divindade marinha e, aparentemente, tão inacessivel quanto ela. A associação entre o movimento incessante e a multiplicidade de formas com a dóxa é explicitada no Mênon, 97d/e. De novo as dóxai são comparadas às estátuas móveis de Dédalo. Desta vez, são elas que devem ser acorrentadas para que não escapem e fujam, pois essas obras só teriam valor quando obrigadas a permanecer em um lugar fixo.

No Íon 541e, Sócrates afirma: “Como Proteus, escapas por todos os lados e assume as mais variadas formas" (hósper ho Proteús pantodapós gígne strephómenos áno te kaì káto). A aporia final, nos diálogos socráticos, costuma ter essa caracterização, a situação de impasse é descrita na linguagem da pláne, errância ${ }^{25}$.

No Íon, é o rapsodo e a poesia que assumem uma série de formas, eles que escapam como Proteus de uma forma fixa. Curiosamente, o encadeamento é usado aqui - ao contrário de um encadeamento discursivo como é sugerido no Menon - como metáfora da imobilização dos componentes da performance poética. Os elos da corrente que formam o circuito magnético por onde jorra o fluxo da Musa estão agora, pelo efeito do élenkhos, encadeados uns aos outros de tal modo que nenhum deles tem autonomia para falar sobre o sentido da poesia. Sua autoridade foi reduzida a mero meio de transmissão e o sentido da poesia neutralizado. Acorrentados uns aos outros, os participantes perdem a capacidade "proteica" da própria poesia de escaparem ao assumir múltiplas formas. Imobilizados, poetas e rapsodos perdem o direito de falar em nome das "tantas coisas admiráveis" de que fala a poesia. A partir de agora, as coisas admiráveis ficam restritas à esfera da experiência humana, e, por isso, devem ser submetidas ao teste do élenkhos.

\section{REFERÊNCIAS BIBLIOGRÁFICAS}

DELeUZE, G. (1990) Pourparlers. Paris, Éd. de Minuit.

DODDS, E. R. (1951) The Greeks and the Irrational. Berkeley, University of Califórnia Press.

FERRARI, G. R. F. (1989) Plato and Poetry. In: KENNEDY, George A., ed. The Cambridge History of Literary Criticism: I - Classical Criticism. Cambridge, Cambridge University Press, p. 92-148.

FORD, A. (2002) The origins of criticism. Literary culture and poetic theory in classical Greece. Princeton, PUP.

FRÄNKEL, H. (1975) Early Greek Poetry and Poetry: A History of Greek Epic, Lyric and Prose to the Middle of the Fifth Century. Oxford, Basil Blackwell.

HAVELOCK, Eric A. (1963) Preface to Plato. Oxford, Basil Blackwell. with other figures in the dialogues. Thus, he does not mark his absence as author, but obscures it. [...] In addition, Plato creates a text that disposes the reader to adopt a critical attitude that is focused on what is being portrayed in the text and that does not concern itself with the intention of an absent author. In order to follow the argument portrayed in the text, the reader is forced, as are Socrates' interlocutors, to employ the distinction between words and meaning."

23. É essa fluência (euporeia, p. ex. em 533c, 536d) que Ion diz ter quando fala de Homero tem como contraponto a aporia do élenkhos.

24. Ver a similaridade entre a comunicação entusiasmada e a comunicação intensiva do nietzscheanismo francês. Por exemplo, em Pourparlers (1990) Deleuze afirma «il y a deux manières de lire un livre "), une manière classique et une manière intensive : "Ou bien on le considère comme une boîte qui renvoie à un dedans, et alors on va chercher ses signifiés [...] Ou bien l'autre manière : on considère un livre comme une petite machine a-signifiante; le seul problème est « est-ce que ça fonctionne, et comment ça fonctionne?» Comment ça fonctionne pour vous ? Si ça ne fonctionne pas, si rien ne passe, prenez donc un autre livre. Cette autre lecture, c'est une lecture en intensité : quelque chose passe ou ne passe pas. [...] C'est du type branchement électrique. [...] Cette autre manière de lire s'oppose à la précédente, parce qu'elle rapporte immédiatement un livre au Dehors.» (p. 17).

25. Na Apologia, Sócrates conta que o élenkhos surgiu de um oráculo de Delfos. Na origem do élenkhos encontramos, portanto, o oráculo. E como a ironia está intimamente associada à forma de expressão oracular, élenkhos e ironia são indissociáveis. Quando Sócrates recebeu de Querefonte a sentença profética, ele não duvidou da veracidade do oráculo (“aos deuses não é permitido mentir"), apenas constatou que a verdade não estava dada por inteiro, uma parte oculta do seu sentido precisava ser descoberta. Dito de outra maneira, o oráculo precisava ser colocado à prova: “ 0 que o deus está querendo dizer ao dizer? 0 que estaria ele indicando?", perguntava ele. Essas questões são os motores do élenkhos. 0 aspecto irônico 
do élenkhos caracteriza-se por deixar entrever que o sentido não não se revela no que manifesta, e - exatamente por isso - deve ser colocado à prova. Para a noção de ironia oracular v. Muniz (2000).

26. A expressão eplána kaì epoíe áno te kai káto ("errar em todas as direções"), que encontramos no Prot. 356d, aparece em vários outros contextos № Laques (196b), por exemplo, personagem homônimo reconhece, na atitude indecisa de Nicias, uma falta de nobreza ("em não concordar que diz coisas sem sentido"), e suas palavras "transformam-se em todos os sentidos". V. A doutrina da errância, cap III de Muniz (2011).
LAKS, A. e MOST, Glenn. (1997) Studies on the Derveni Papirus. 0xford, Clarendon Press.

LEAR, J. (2006) Allegory and myth in Plato's Republic p. 27. In Santas, G. (org.) Blackwell Guide to Plato's Republic. Oxford, Blackwell.

MURRAY, Penelope. (1981) Poetic Inspiration in Early Greece. Journal of Hellenic Studies 101, p. 87-100.

MUNIZ, Fernando. (2011) A potência da aparência: um estudo sobre o prazer e a sensação nos Diálogos de Platão. São Paulo, Annablume.

NAGY, Gregory. (1989) Early Greek Views of Poets and Poetry. In: KENNEDY, G., ed. Cambridge History of Literary Críticism I. Cambridge, Cambridge University Press, p. 1-77.

(1990) Pindar's Homer: the lyric possession of an epic past. Baltimore; London, The Johns Hopkins University Press.

ONG, Walter J. (1988) Orality and Literacy: The Technologizing of the Word. London, Routledge.

. (1971) Rhetoric, romance, and technology: studies in the interaction of expression and culture. Ithaca, London, Cornell University Press.

PFEIFFER, R. (1968). History of classical scholarship. 0xford, Clarendon Press.

STERN-GILLET, S. (2004) On (mis) interpreting Plato's Ion. In Phonesis, vol. 49, n.2.

TIGERSTEDT, E. N. (1970) "Furor Poeticus": Poetic Inspiration in Greek Literature before Democritus and Plato. Journal of the History of Ideas 31, p. 163-78.

VERDENIUS, W. J. (1983) The Principles of Greek Literary Criticism. Mnemosyne 36, p. 14-59.

YUNIS, H. (2003) Written texts and the rise of literate culture in Ancient Greece. Cambridge, CUP.

Recebido em janeiro de 2012. Aprovado em março de 2012. 